Scientific Journal of October 6 University

ISSN (Print): 2314-8640

ISSN (Electronic): 2356-8119

Published by October 6 University @ All Rights Reserved

Available online at: http:// sjou.journals.ekb.eg

Research Article
Citation: Shaimaa Abduo et al., (2014). A Simplified Approach for Water Hammer Analysis. Sci.J. of Oct. 6 Univ.2 (2), 213-220

Copyright: (C) 2014 Shaimaa Abduo et al.,This is an open-access article distributed under the terms of the Creative Commons Attribution License, which permits unrestricted use, distribution, and reproduction in any medium, provided the original author and source are credited.

\title{
A Simplified Approach for Water Hammer Analysis
}

\section{*Shaimaa Abduo, M. Abdel Razik, M. Fergala, and S. Elagroudy}

Sanitary and Environment Engineering Section, Public Works Department, Faculty of Engineering, Ain Shams University

Received: 14-03-2014/ Revised: 07-04-2014 / Accepted: 30-04-2014/ published: 01-06-2014

\begin{abstract}
The objective of this paper is to provide a practical and simplified approach for the analysis of water hammer phenomenon, develop the pressure transient envelops produced due to water hammer, asses the need for protection, and determine the size of protection device. A typical water supply system consisting of a pump and long transmission pipeline delivering to a terminal reservoir is proposed. About 500 runs are simulated on Bentley Hammer software to cover wide variation of physical and hydraulic parameters. The results of simulation are used to develop a model for the pressure envelops along the pipeline profile and another model for sizing of the protection device needed to reduce the impact of water hammer.
\end{abstract}

Keywords: Transient Pressures, Water Hammer, Surge Protection Devices, Simplified Approach.

\section{Introduction}

Water hammer prediction used to carry out graphically (Allievi, 1925) (1). The graphical method is very complex and not accurate. Angus and Parmakian, (1963) (2) and Wood \& Jones, (1973) (3), refined the graphical calculation method. Numerical methods implemented in computer codes addressed this problem. The development of computer technologies made the numerical method of water hammer simulation in complex pipe networks become easier. In recent years, numerical methods are widely used in water hammer phenomenon study and almost replaced the graphical method. The main numerical methods to Joukowsky developed an equation in 1898to calculate pressure drop or rise due to sudden pump simulate water hammer events include method of characteristic (Wylie and Streeter, 1993) (4), the finite volume Method (Zhao and Ghidaoui, 2004) (5), the finite element method (Kochupillail et al., 2005) (6), Wavelet-Galerkin (Sattar et al., 2009) (7), the fluid structure interaction, and so on. Among those methods, the method of characteristic (MOC) is the most popular one. Afshar and Rohani, (2008) (8), developed a different MOC procedure. Some research indicates that MOC fits experimental data well.Ghidaoui et al., (2005) (9) investigated eleven available water hammer commercial software packages, and found that in eight of them MOC was applied.

power failure. Joukowsky's Equation is shown in equation (1): 
$\Delta \mathrm{H}_{1}= \pm \frac{\mathrm{a}}{\mathrm{g}} \Delta \mathrm{V}$

Where, $\Delta \mathrm{H}_{1}$; is the change of surge pressure, $\Delta \mathrm{V}$; is the change of water velocity in the pipeline, $a$; is the wave speed, and $\mathrm{g}$; is the gravitational acceleration line with instantaneous failure. Joukowsky's equation is based on some assumptions such as the occurrence of hammering is instantaneous, the pipeline properties are uniform, and the pipe is rigid. During transient, pressure and velocity in pipes change with distance and time where they follow the laws for conservation of mass and conservation of momentum given in Equation $(2,3)$ respectively. (10)

$\frac{\partial \mathrm{P}}{\partial \mathrm{t}}+\mathrm{v}\left(\frac{\partial \mathrm{P}}{\partial \mathrm{x}}\right)+\rho \mathrm{a}^{2}\left(\frac{\partial \mathrm{v}}{\partial \mathrm{x}}\right)=0$

$\frac{\partial \mathrm{v}}{\partial \mathrm{t}}+\mathrm{v}\left(\frac{\partial \mathrm{v}}{\partial \mathrm{x}}\right)+\frac{1}{\rho}\left(\frac{\partial \mathrm{P}}{\partial \mathrm{x}}\right)+\mathrm{g} \sin \theta+\frac{\mathrm{fv}|\mathrm{v}|}{2 \mathrm{D}}=0$

Where ${ }^{\partial} \mathrm{P} / \partial_{t}$; is the change of surge pressure with time during transient, $\partial_{\mathrm{v} /} \partial_{\mathrm{t}}$; is the change of flow velocity with time during transient, $\partial_{\mathrm{P} /} \partial_{\mathrm{x}}$; is the change of surge pressure with the distance in the pipeline, $\partial_{\mathbf{v}} / \partial_{\mathbf{x}}$; is the change of flow velocity with the distance in the pipeline, $\mathrm{v}$; is the fluid flow velocity, $\rho$; is the mass density of the fluid, a; is the wave speed, $\mathrm{g}$; is the gravitational acceleration line, $\mathrm{D}$; is the conduit diameter of pipeline, $\theta$; angle the conduit makes with the horizontal, and $\mathrm{f}$; is the friction factor. The main concept behind of MOC is the transformation of partial differential equations $(2,3)$ into ordinary differential equations and these equations are shown concisely in equation $(4,5)$. (10)

$$
\begin{aligned}
& \mathrm{Q}_{\mathrm{p}}=\mathrm{C}_{\mathrm{p}}-\mathrm{C}_{\mathrm{a}} \mathrm{H}_{\mathrm{p}} \\
& \mathrm{Q}_{\mathrm{p}}=\mathrm{C}_{\mathrm{n}}-\mathrm{C}_{\mathrm{a}} \mathrm{H}_{\mathrm{p}} \mathrm{C}^{+}
\end{aligned}
$$

Where, $\mathrm{Q}_{\mathrm{P}}$; and $\mathrm{H}_{\mathrm{P}}$; are the discharge and head at point $P$ respectively, $\left(C_{P}, C_{n}, C_{a}\right)$ are constants dependent upon pipe properties, initial condition and time interval. Thorley and Lastowiecki, (1985) (11) presented the first computer based iterative procedure for sizing air vessels for pipeline systems. Stephenson, (2002) (12) showed the effect of using air vessels in protecting the distribution system against negative pressures during water hammer, and reported that air vessels can maintaina positive pressure in the line at all stages following pump trip. Di Santo et al., (2002) (13) developed design charts for air vessel sizing for pump trip scenario that can be applied only at preliminary design stage due to their simplifying assumptions (e.g. neglecting frictional losses), selection and range of parameters, limited accuracy of solutions and lack of completeness. Martino et al., (2004) (14) reported that Evangelisti in 1938 developed graphs that aid in the sizing of air vessels, using incompressible flow theory neglecting pipe friction and assuming adiabatic expansion of air $(\mathrm{n}=1.41)$.

Evangelisti's Equations allow for analytical solution if pipe friction is neglected and introduced a dimensionless constant (ratio of steady state head loss to absolute steady state pressure) for use in numerical integration procedures for solution when pipe friction was considered. These graphs demonstrated the favorable role of pipe friction loss in attenuating over pressure oscillations ElBahrawy, (2004) (15) presented a simplified description of water hammer, its effects, control devices and equations. He also presented a spread sheet for teaching transient flow in pipes. Fleming and Gullick, (2005) (16) developed surge models for five distribution networks and used it to identify the locations within the distribution systems where low or negative pressures were most likely to occur. Durand et al., (2006) (17) developed a simplified analysis of water hammer. The analysis calculates four main parameters of water hammer; velocity of the pressure wave celerity, critical time, maximum head developed in the maximum pressure time and minimum head developed in the critical time. Gao et al., (2012) (18) investigated cases studies of three kinds of hammer protecting devices which are twophase control valve, one-way surge tank and hydropneumatic tank. According to the simulation results, the effective protecting scheme of water hammer is through hydropneumatic tank to reduce the surge damage combined with the application of the air valve. Himr, (2013) (19) simulated unsteady flow during water hammer using Matlab-SimulinkSimHydraulics and HYDRA. Simulation results proved in very good agreement with experimental measurements. Oulhaj et al., (2013) (20) presented the influence of using the protection devices to control the adverse effects due to excessive and low pressure occurs in the transient. Pato and Navarro,(2014) (21) presented a reformulation of the mathematical model developed by Preissmann, 1964 for the estimation of pressure values in 
transitory situations between both shallow and pressurized flows by adapting it to abrupt transient situations. The objective of this paper is to provide a practical and simplified approach for the analysis of water hammer phenomenon, develop the pressure transient envelops produced due to water hammer, asses the need for protection and determine the size of the gas volume in the air vessel. Bentley Hammer V8I software, which adapts the MOC is used for transient analysis.

\section{Materials and Methods}

Atypical water supply system consisting of a pump and long transmission pipeline delivering to terminal reservoir is used for the analysis. Figure (1) shows the water supply system, pipe profile, initial and final steady state hydraulic grade, maximum and minimum transient head with and without protection.

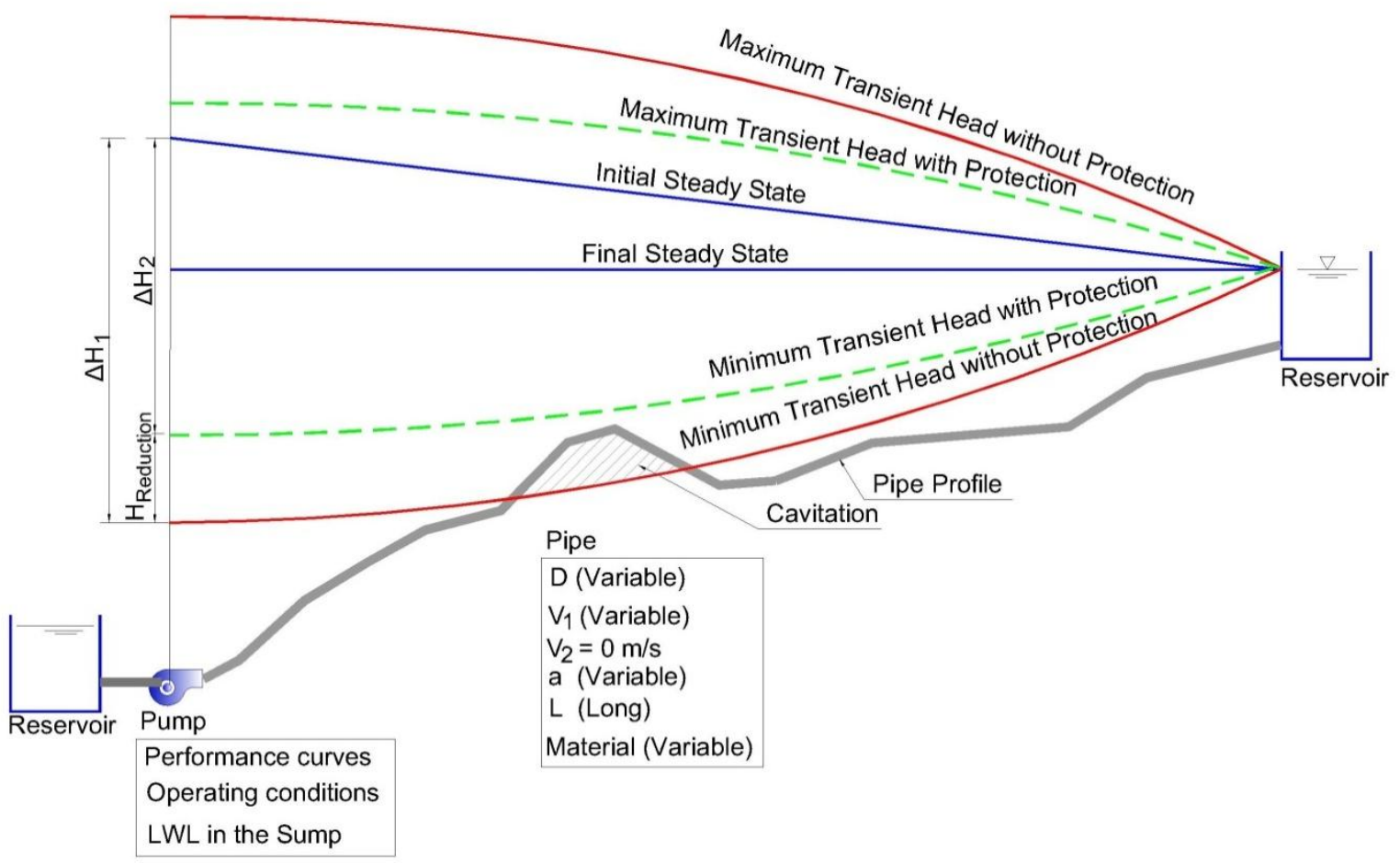

Figure (1): Typical Pressure Envelops With and Without Protection

To conduct the aforementioned objectives of research, about 500 simulation runsare applied on Bentley Hammer to the water supply system covering a wide range of physical and hydraulic parameters as presented in Table (1).

Table (1): Variation of the Physical and Hydraulic Parameters

\begin{tabular}{||c|c||}
\hline Parameters & Range \\
\hline Diameter $(\mathrm{D})(\mathrm{mm})$ & 300 to 1200 \\
\hline Velocity $(\mathrm{V})(\mathrm{m} / \mathrm{s})$ & 0.5 to 2.5 \\
\hline Wave Speed $(\mathrm{a})(\mathrm{m} / \mathrm{s})$ & 300 to 1500 \\
\hline Demand and Pump Head $(\mathrm{H})$ & Depend on the velocity and diameter \\
\hline Pipe length $(\mathrm{L})(\mathrm{m})$ & Long pipeline $(30 \mathrm{~km})$ \\
\hline
\end{tabular}

The analysis is undertaken in three steps: 
Step 1 - Evaluate the impact of water hammer pressure, presented by calculating the pressure drop $\left(\Delta \mathrm{H}_{1}\right)$ as a result of water hammer.

Step 2 - Develop a relation for the pressure envelops which upon plotting against pipe profile, the need for water hammer protection can be assessment.

Step 3 - Develop a relation for the size of water hammer protection device.

\section{Results and Discussion}

Step 1-Pressure Drop at the pump station

Comparison between the calculated pressure drop $\left(\Delta \mathrm{H}_{1}\right)$ due to pump power failure by Joukowsky's Equation and the resulting pressure drop by Bentley HAMMER softwareis presented in Figures 2 (a to d) for diameters 300, 600, 900 and $1200 \mathrm{~mm}$ respectively. The velocity ranged from 0.5 to 2.5 $\mathrm{m} / \mathrm{s}$ and wave speed from 300 to $1500 \mathrm{~m} / \mathrm{s}$. The values of wave speed were used to represent a rigid pipe and an elastic pipe. The coefficient of determination $\left(\mathrm{R}^{2}\right)$ is used for model assessment.

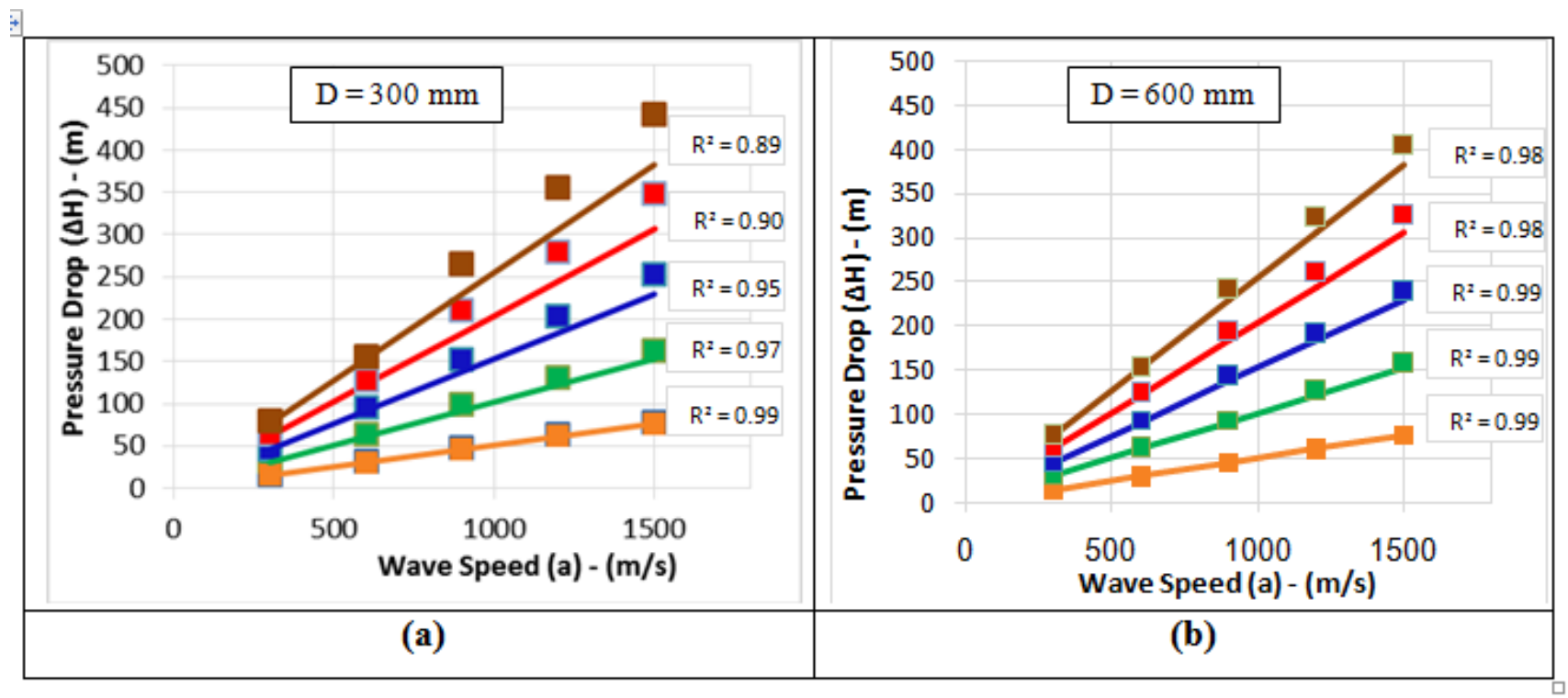

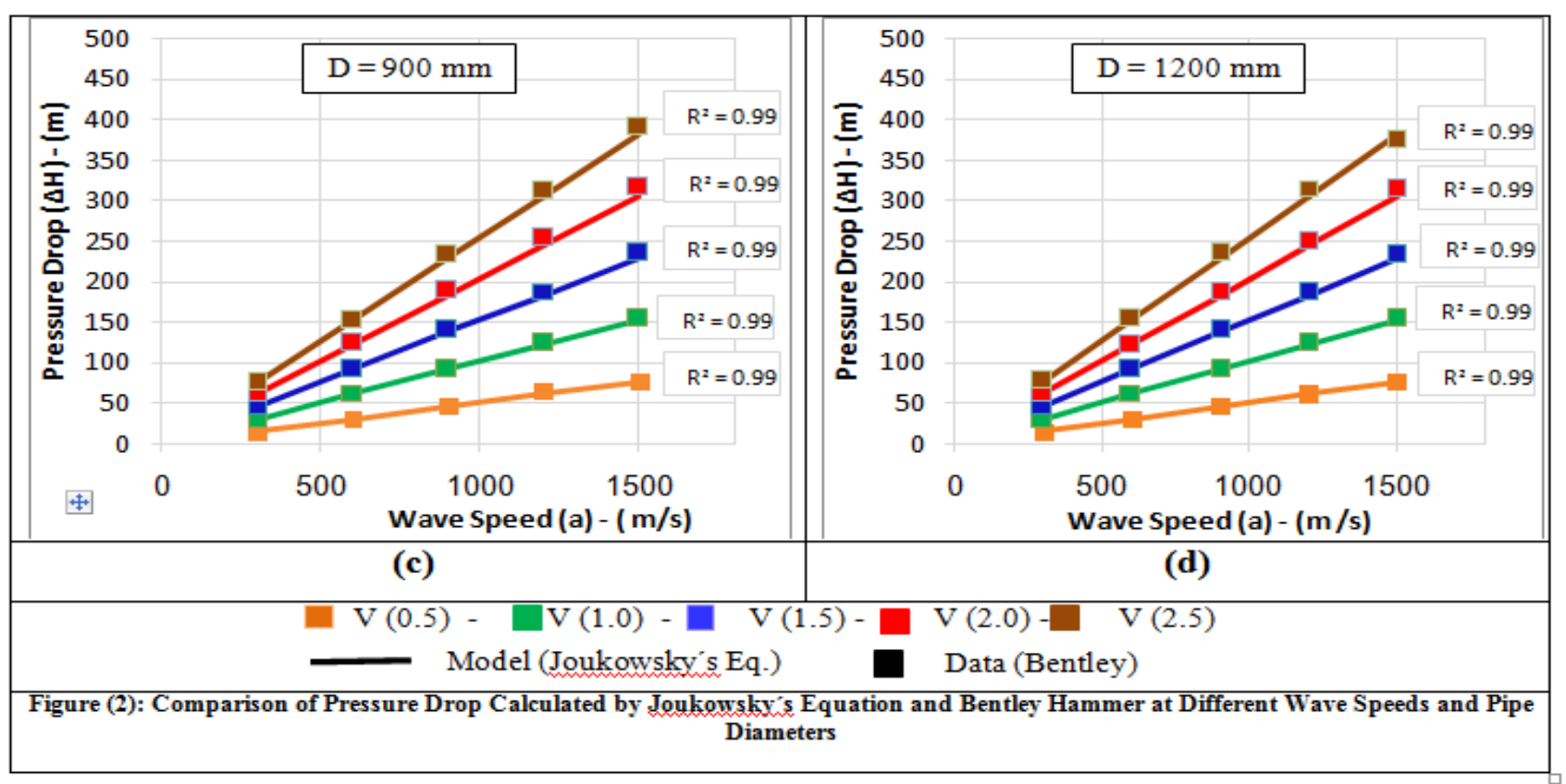


Joukowsky's Equation is validated by comparing the results of calculated pressure drop $\left(\Delta \mathrm{H}_{1}\right)$ and those resulting from Bentley Hammer software,it is noted that Joukowsky'sEquation can be expressed the pressure drop with high agreement. the pressure dropvalues are in close proximity with $\left(\mathrm{R}^{2}>0.95\right)$ at flow velocity of less than $2.0 \mathrm{~m} / \mathrm{s}$, while the results for the velocity higher than 2 $\mathrm{m} / \mathrm{s}$ is slightly close with $\left(\mathrm{R}^{2}>0.89\right)$.

Where, $\Delta \mathrm{H}$; Pressure drop along the pipe line (m), $\Delta \mathrm{H}_{1}$; Pressure drop at the pump (m) (calculated by Joukowsky's Equation), X; Distance interval (m), and L; Length of the
Finally Joukowsky's Equation can be expressed the transient behavior for simple system.

Step 2 - Pressure envelops

To assess the need for a protection strategy, it is important to calculate the pressure envelops and plot it over the pipe profile. A new empirical formula is developed for determining the pressure envelops along the pipeline as shown in Equation (6).

$\Delta \mathrm{H}=\Delta \mathrm{H}_{1}\left[1+\left(\frac{\mathrm{X}}{\mathrm{L}}\right)\right]^{0.35}$

pipe (m). Figure (3) shows pressure envelops without protection for diameter of $600 \mathrm{~mm}$ and wave speed (a) of $900 \mathrm{~m} / \mathrm{s}$.

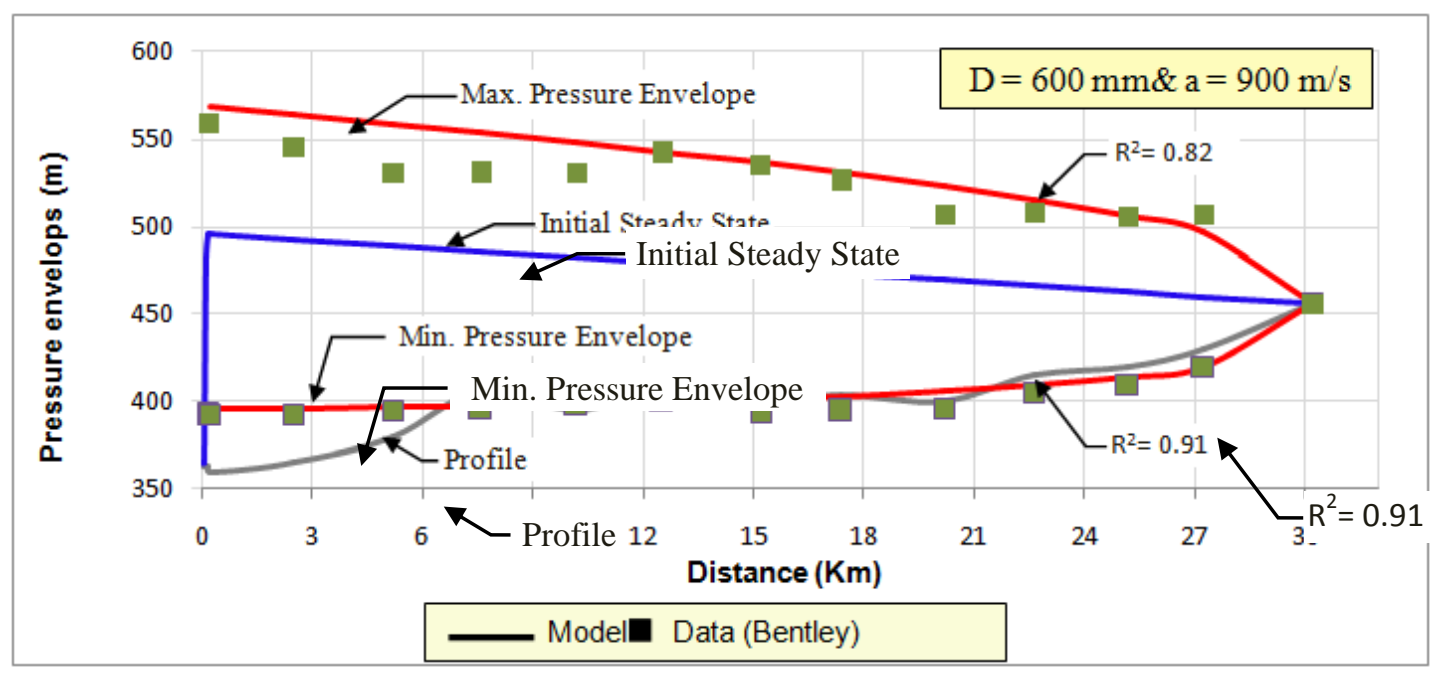

Figure 3: Pressure Envelops without Protection

The developed formula in Equation (6) is validated by comparing the results of the pressure with those calculated by Bentley Hammer, it is noted that the developed Equation can be expressed the pressure envelopes with high agreement. The maximum and minimum pressure values are in close proximity with $\mathrm{R}^{2}(0.82$ and 0.91$)$ respectively. Therefore, the developed empirical formula Equation (6) proved to be a good approximation for calculating the maximum and minimum pressure envelops and $\mathrm{V}=0.4 \mathrm{D}^{5} \mathrm{H}^{1.75}$

Where,V; Gas volume in the hydropneumatic tank $\left(\mathrm{m}^{3}\right), \mathrm{D}$; Pipe diameter $(\mathrm{m}), \mathrm{H}$; Required reduction of the pressure drop to eliminate water hammer effect $(\mathrm{m})$. assessment of the need for a protection device by plotting the pipe profile against the pressure envelopes.

\section{Step 3 - Sizing the Protection Device}

In piping system, various control procedures are used to reduce or eliminate undesirable transients, such as excessive pressure rise or drop. In this study, the air vessel is suitable for controlling transients generated by power failure of the pumps. A new formula is developed for determining the size of gas volume as presented in Equation (7).

Applying Equation (7) on the proposed water system, the gas volume in the air vessel for the system is $7 \mathrm{~m}^{3}$ approximately to reduce the pressure drop $21 \mathrm{~m}$ approximately. 


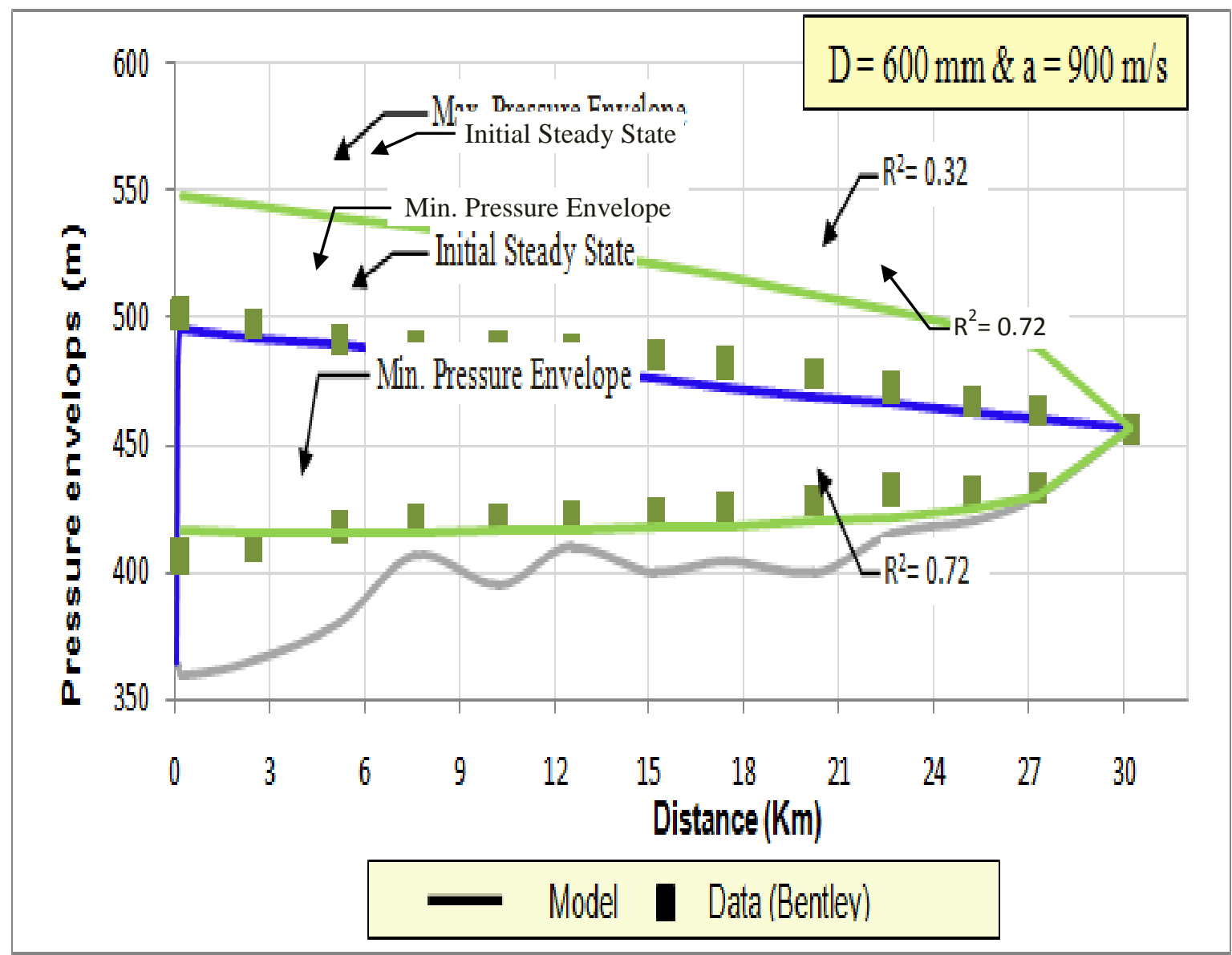

Figure (4): Pressure Envelops with Protection

As shown in figure 4, it is noted that the calculated gas volume calculated by Equation (7) eliminates the pressure transient impact. The developed formula in Equation (7) is validated by comparing the results of the pressure with those calculated by Bentley Hammer, it is noted that the developed Equation can be expressed the pressure envelopes with protection with high agreement in calculating the downsurge pressure while upsurge pressure is underestimation. The maximum and minimum pressure values are in close proximity with $\mathrm{R}^{2}$ (0.72 and 0.32)respectively. Therefore, the developed empirical formula Equation (7) proved to be a good approximation for sizing the gas volume.

To assess the impact of pipe diameters on the gas volume, About 80 simulation runsare applied on Bentley Hammer software to the water supply system covering the impact of various pipe diameters of $300,600,900$ and $1200 \mathrm{~mm}$ respectively on the gas volume Figure 5 (a to d) compare the values of pressure drop calculated using Bentley water Hammer and those calculated from Equation (7) for pipe diameters of 300, 600, 900 and $1200 \mathrm{~mm}$; respectively. 


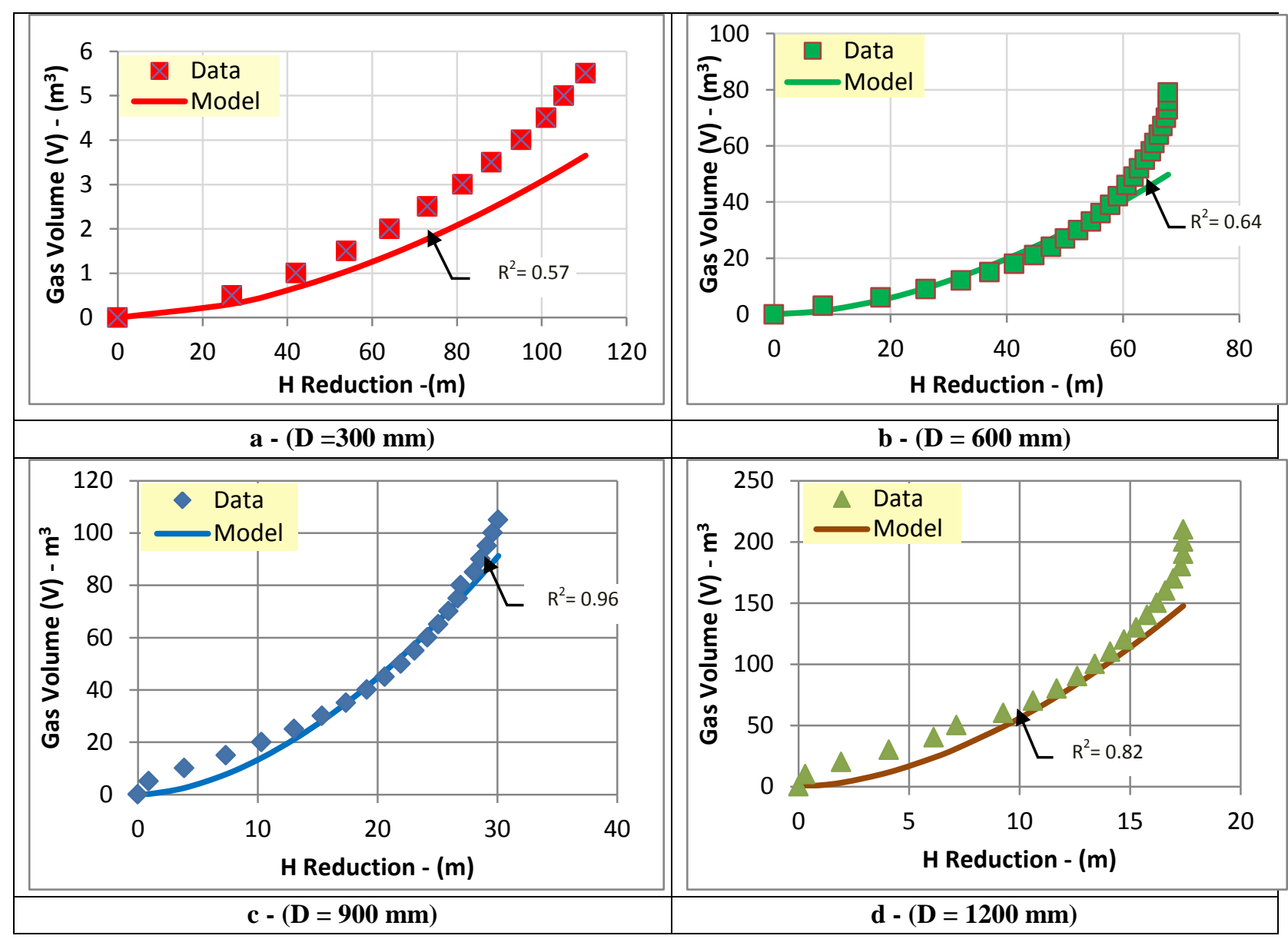

Figure (5): Gas Volume Required to Achieve Pressure Drop Reduction by Bentley Hammer and the Developed Equation

By comparing the results of the pressure drop reduction $(\mathrm{H})$ with those calculated by Bentley Hammer, it is noted that the developed Equation (7) can be expressed with high agreement with $\left(\mathrm{R}^{2}\right)$ ranges from 0.96 to 0.57 for the diameters ranges of 300 to $1200 \mathrm{~mm}$ respectively, and also noted that the developed formula can be expressed with high agreement for calculating the gas volume.

\section{Conclusion}

A simplified approach for the analysis of water hammer phenomenon has been developed the pressure transient envelops, asses the need for protection, and determine the size of the gas volume in the air vessel. After analyzing the water hammer system, the approach can be drawn as follows:

- The direct relationship which known with Joukowsky's equation is valid to approximately estimate the pressure drop at the pump.

- A new empirical formula is developed to calculate the maximum and minimum pressure envelops along the pipeline and to assess the needing of protection.

- A new empirical model is developed to size the gas volume in the air vessel. As such the developed simplified approach for calculating water hammer can be summarized in Figure (6). 


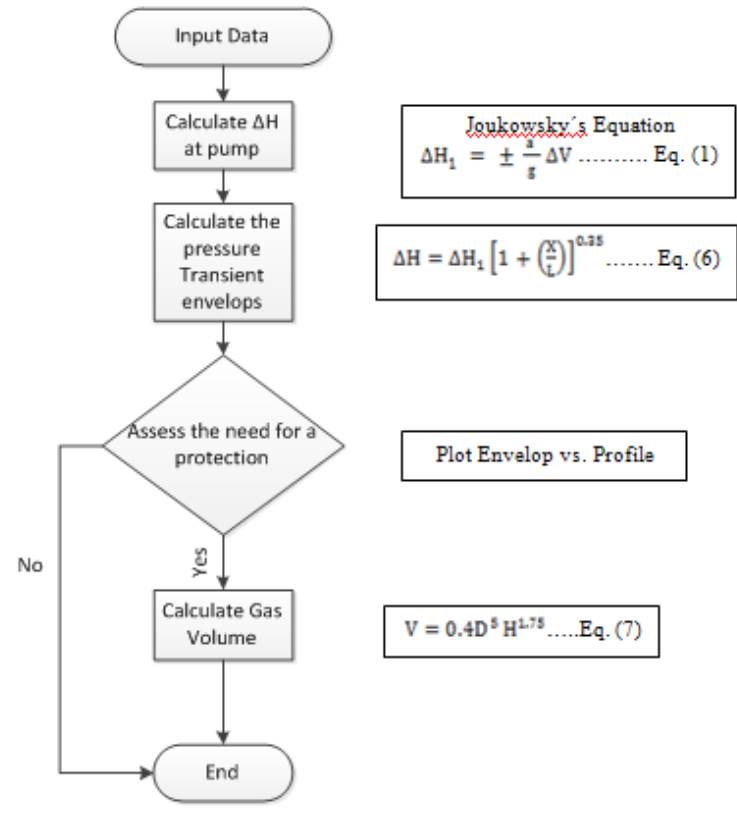

\section{Figure 6: Flow Chart of the Simplified Approach for Calculating Water Hammer}

1. Allievi, L., (1925). "Theory of Water Hammer". Typography R. Garroni, Rome

2. Parmakian, (1963) "water hammer analysis", PrenticeHall, inc. Englewood Cliffs

3. Don J. Wood and S.E. Jones, (1973) "Waterhammer Charts for Various Types of Valves," Journal of Hydraulics Division, ASCE, Vol. 99, pp. 167- 178.

4. Wylie, E.B., Streeter, V.L., (1993). "Fluid Mechanics, 6th ed." McGraw-Hill Book Co, New York.

5. Zhao, M., Ghidaoui, M.S., (2004). "Godunov-type solutions for water hammer flows". J. Hydraul. Eng.ASCE 130, pp341-348.

6. Kochupillail, J., Ganesan, N., Padmanabhan, C., (2005). "A new finite element formulation based on the velocity of flow for water hammer problems". Pressure Vessels and Piping" 82(1), 1-14.

7. Sattar, A.M.A., Dickerson, J.R., Chaudhry, M.H., (2009). "Wavelet-Galerkin solution to the water hammer equations". J. Hydraul. Eng.-ASCE 135, 283-295.

8. Afshar, M.H., Rohani, M., (2008). "Water hammer simulation by implicit method of characteristic". International Journal of Pressure Vessels and Piping, Vol. 85 , no. 12 , pp. $851-859$.

9. Ghidaoui, M.S., Ming, Z., McInnis, D.A., Axworthy, D.H., (2005). "A review of water hammer theory and practice." Applied Mechanics Reviews, Vol. 58(1-6), 2005, p. 49-75

10. Chaudhry, M. H., (1987). "Applied hydraulic transients (2nd Edition)", Litton educational Publishing Inc., Van Nostrand Co, New York

11. Thorley, A.R.D. and Lastowiecki, P. (1985). "Air vessel design for rising mains."Proceedings, International Conference on Pumping Stations, BHRA, Manchester, England. 89-98.

12. Stephenson D. (2002). "Simple guide for design of air vessels for water hammer protection of pumping lines." Journal of Hydraulic Engineering, American Society of Civil Engineers, 128, 792-797.
13. Di Santo, A.R., Fratino, U., Lacobellis, V. and Piccinni, A.f. (2002). "Effects of free outflow in rising mains with air chamber". Journal of Hydraulic Engineering, Vol. 128, No. 11, pp. 992-1001.

14. Martino G.D., Paola F.D., Fontana N. and Giugni M (2004). Discussion of "Simple Guide for Design of Air Vessels for Water Hammer Protection of Pumping Lines." by D. Stephenson. Jl. Hydraulic Engineering, ASCE, 130, 273-275.

15. El-Bahrawy, A. N., (2004), "Use of spread sheets in teaching flow transient in pipes", Al-Azhar Eighth International Conference, Cairo.

16. Fleming, K.K. and Gullick, R.W., (2005). "Susceptibility of potable water distribution systems to negative pressure transient". American water, Voorhees, NI 08043.

17. Durand et al., (2006) "A simplified approach to waterhammer analysis".Chemical Engineering Progress Magazine

18. Gao et al., (2012) "Water hammer protection in long distance water pipeline with ultra-high lift". WDSA 2012: 14th Water Distribution Systems Analysis Conference, 2427 September 2012 in Adelaide, South Australia.

19. Himr, D., Dančová, P., and Novontý, P. (2013). "Numerical simulation of water hammer in low pressurized pipe: comparison of SimHydraulics and LaxWendroff method with experiment." EPJ Web of Conferences, $\quad 10.1051 /$ epjconf/20134501037, 01037.Online publication date: 1-Jan-2013.

20. Oulhaj et al., (2013) "Sizing the Protection Devices to Control Water Hammer Damage" International Journal of Civil, Architectural, Structural and Construction Engineering Vol:7 No:11.

21. Fernández-Pato and P. García-Navarro,(2014) “A pipe network simulation model with dynamic transition between free surface and pressurized flow" journal Drinking Water Engineering and Science Discussions (DWES) 